\title{
KASVATUS\&AIKA
}

KaTSAUS

https://doi.org/10.33350/ka.107886

\section{Saamelaislasten koulutushistoria kertoo maiden yhtäläisyydestä ja erityisyydestä}

\author{
Otso Kortekangas \& Jukka Nyyssönen
}

\section{Johdanto}

Kaikkien Pohjoismaiden valtiollisten koululaitosten kehittyessä 1800-luvun lopulla ja 1900-luvun alussa tulivat myös saamelaislapset eri tavoin kansakoulun opetuksen piiriin. Koululaitoksen ulottaminen valtioiden poliittisista keskuksista katsottuna syrjäisille seuduille oli osa kansallisvaltioiden suurta koulutusprojektia, yhdenmukaisen ja ainakin näennäisesti yhtäläisen kansallisuus- ja myöhemmin demokratiaihanteen ulottamista koko valtion alueelle. Samalla oppilaille välitettiin tietty keskitetysti tuotettu oppisisältö, joka oli sama kaikissa kansakouluissa. Näin katsottuna myös saamelaislapsia koskenut kansanopetuksen leviäminen oli osa yleistä 1900-luvun koulutushistoriaa ja demokratisointiprojektia niin Suomessa, Ruotsissa kuin Norjassakin. Toisaalta saamelaisten opetus poikkesi normista eri tavoin kaikissa Pohjoismaissa.

Oman lisänsä saamelaisten koulutushistoriaan antaa Neuvostoliiton alkuvuosien kulttuurisensitiivinen vähemmistöpolitiikka, joka lakkautettiin traagisin seurauksin Stalinin tultua valtaan. Tämä katsaus ei käsittele tarkemmin Venäjän tilannetta, mutta seuraava lyhyt yhteenveto aiheesta auttaa muodostamaan kokonaiskuvan saamelaisten tilanteesta koko saamelaisalueella.

Neuvosto-Venäjän ja Neuvostoliiton alkuvuosina vähemmistöpolitiikka oli sosialistisen "kansojen ystävyys" -ideologian mukaisesti vähemmistökulttuureille myönteistä. 1900luvun alun venäläistämispolitiikan sijaan Neuvostoliiton saamelaisalueille perustettiin saamelaiskouluja, ja oppimateriaalia tuotettiin saameksi 1910-1920- luvuilla, puoli vuosisataa aikaisemmin kuin asiasta edes toden teolla alettiin keskustella Pohjoismaissa. Josef Stalinin noustua valtaan Neuvostoliitossa 1920-luvun puolivälissä politiikan suunta kuitenkin muuttui täydellisesti. Saamelaiskoulut lakkautettiin ja suurin osa saamelaisväestöstä sulautettiin pakkosiirroilla ja väkivallalla. Saamenkielistä koulutusta luodannut tutkimus pysähtyi myös vuosikymmeniksi, koska alan johtavat nimet pidätettiin ja vangittiin Stalinin vainoissa. (Kotljarchuk 2019.) Saamenkielinen koulutus ja toisaalta koulutushistoriallinen tutkimus on vasta uudelleen pääsemässä vauhtiin Venäjän ja Neuvostoliiton osalta, muun muas sa Andrej Kotljarchukin (2019), Lukas Allemannin (2019) ja Ekaterina Zmyvalovan (2019) tutkimusten myötä.

Tässä katsauksessa tarkastelemme Ruotsissa, Norjassa ja Suomessa harjoitetun saamelaisia koskevan koulutuspolitiikan historiallisia yleislinjauksia sekä tähän liittyvän viimeaikaisen tutkimuksen suuntauksia. Alan tutkimuksen suhteen tarkastelemme viimeaikaisia 
teemoja ja painotuksia. Nämä teemat ja painotukset tulevat toisaalta ymmärrettäviksi ainoastaan, jos lukijalle tarjotaan kontekstiksi tietoa siitä, mitä eri maiden koulutuspolitiikat pitivät sisällään. Katsauksella on siksi kaksi erillistä mutta toisistaan riippuvaista painopistettä: yhtäältä koulutuspolitiikat sinänsä, ja toisaalta ne erilaiset näkökulmat, joista käsin tutkijat ovat näiden politiikkojen historiaa lähestyneet. Pääpiirteissään 1900-luvun saamelaisiin kohdistuneessa koulutuspolitiikassa näkyy ennen kaikkea kolme suuntausta: assimilointi eli sulauttaminen valtaväestöön, segregointi eli eriyttämien valtaväestöstä, sekä myöhemmin 1900-luvulla enenevissä määrin myös opetuksen "dekolonisointi" tai "saamelaistaminen", eli opintosisältöjen suunnitteleminen saamelaisten omista tarpeista käsin aiemman, valtaväestön normeihin perustuvan koulutuspolitiikan sijasta.

\section{Ruotsin nomadikoulu - Erityiskoulu poronhoitajien lapsille}

Selkein esimerkki segregoivasta eli eriyttävästä koulutuspolitiikasta on Ruotsissa 1900luvun alkupuolella toiminut nomadikoulu. Nomadikoulu on myös tullut Ruotsin saamelaisia koskevan koulutushistoriallisen tutkimuksen keskiöön, ja 2000-luvulta lähtien aiheesta on kirjoitettu varsin suuri määrä opinnäytteitä, artikkeleita ja kirjoja. Lars Elenius vertailee vuonna 2006 julkaistussa kirjassaan suomalaisia ja saamelaisia koskevaa politiikkaa. Myös Julia Nordblad käsittelee samaa aihetta väitöskirjassaan, verraten Ruotsin tilannetta lisäksi bretoninkielisiin Ranskassa ja arabiankielisiin Tunisiassa. Sekä Elenius että Nordblad havainnoivat, että suomalaiset sulautettiin Ruotsin valtaväestöön sillä perusteella, että Länsipohjan suomenkieliset olivat itse asiassa alun perin ruotsalaisia, jotka olivat pikkuhiljaa vaihtaneet äidinkielensä suomeen ympäristön vaikutuksesta. Tornionlaakson suomenkielisten kansalaisihanne oli siis sama kuin muilla ruotsalaisilla, ja heidät sulautettiin valtaväes töön ruotsinkielisen koulutuksen kautta. Suomenkielisten tapaan myös ne saamelaislapset, jotka tulivat kodeista, joiden pääelinkeino ei ollut laajamittainen poronhoito, laitettiin tavallisiin ruotsalaisiin kansakouluihin. Näissä kouluissa saamelaisoppilaiden sulautuminen ruotsalaisiin tapoihin ja ruotsin kieleen oli tavallista. (Elenius 2006; Nordblad 2013.). Poronhoitaja-saamelaiset taas eriytettiin omaksi ryhmäkseen, joka oli erillinen elementti varsinaisesta ruotsalaisesta kansasta. Tämän eriyttämisen takana olevaa ideologista taustaa on tutkittu muun muassa rotubiologian (Pusch 1998; Henrysson 1993), reformipedagogiikan (Sjögren 2010) ja kansantalouden (Lantto 2005; Kortekangas 2017) näkökulmasta. Loogisinta on ajatella, että segregoinnin periaate ja käytäntö syntyivät ja muovautuivat näiden kaikkien aatteellisten taustojen yhteisvaikutuksesta.

Kaikkien tunturiseuduilla laajamittaista poronhoitoa harjoittavien saamelaisten lasten tuli käydä Ruotsin nomadikoulua. Nomadikoulujärjestelmä perustettiin 1913 ja sen pääsuunnittelijoina toimivat Luulajan piispa Olof Bergqvist ja Norrbottenin piirin kansakouluntarkastaja Vitalis Karnell. Nomadikoulun johtoajatuksena oli opettaa lapsille heidän vanhempiensa ammattia, eli poronhoitoa, mutta tehokkaampana ja modernisoituna versiona. Opetuskieli oli useimmiten ruotsi, koska nomadikoulun suunnitelleet ja sitä valvovat viranomaiset ajattelivat ruotsin olevan paras kieli poroelinkeinon uudistamiseen. (Kortekangas 2017.) Oppilaat kokivat nomadikoulut usein nöyryyttävinä ja alistavina opinahjoina. Saamelaiset myös kritisoivat kouluja alusta lähtien, sillä opetuksen tason koettiin olevan huonompi kuin tavallisissa kansakouluissa, ja nomadikoulun vetoisia rakennuksia pidettiin terveydelle haitallisina. (Sjögren 2010; Nordblad 2013, Elenius 2006.) Nomadikoulujen myötä Ruotsin poronhoitajasaamelaisten lapsille luotiin erillinen kansalaisihanne verrattuna muihin ruotsalaisiin. Nomadikoulun ohella tämä ihanne kodifioitiin sarjassa 
poronhoitolakeja 1900-luvun taitteen molemmin puolin. Näissä laeissa saamelaisuus ja poronhoito kytkettiin yhteen niin vahvasti, että saamelaisiksi laskettiin lain edessä vain poroja omistavat saamelaiset. (Mörkenstam 1999.)

Saamelaisten poronhoitajien kohdalla ulkoisena kansalaisihanteena oli nimenomaan poronhoitamisen jatkaminen Ruotsin tunturialueilla. Nomadikoulujen pääasiallinen opetuskieli oli kuitenkin ruotsi, koska koulutusauktoriteetit katsoivat porotalouden modernisoinnin onnistuvan vain ulkoa käsin, ruotsalaisen modernisoinnin ja tehostamisen avulla. Tämä segregoiva virtaus poikkeaa linjasta, jossa kansakoulu nähtiin yhtenäistävänä ja demokratisoivana voimana. (Sjögren 2010; Nordblad 2013; Kortekangas 2021.)

1960-luvulla saamelaisvanhemmat saivat viimein mahdollisuuden valita, laittavatko lapsensa uuteen vasta perustettuun peruskouluun vai nomadikouluun. Ei-poronhoitajasaamelaisten lasten koulutushistoria on edelleen sokea piste Ruotsin saamelaisia koskevassa koulutushistoriallisessa tutkimuksessa. Tämä johtuu osin lähdemateriaalin puutteesta: lakien määritellessä vain poronhoitajat virallisesti saamelaiseksi katosivat ei-poronhoitajasaamelaiset asiakirjoista, ja näin ollen lähteistä ja historiankirjoista. Katveessa on ollut myös nomadikoulun myöhempi, toisen maailmansodan jälkeinen historia, mutta asiaan on tulossa korjaus Charlotta Svonnin tekeillä olevan väitöskirjan myötä (ks. esim. Svonni 2017).

\section{Norjan voimakas assimilaatio ja saamelainen liikehdintä}

Norja eroaa Suomesta ja Ruotsista siinä, että maassa oli tarkoin laissa säädelty sulauttamispolitiikka, jonka tavoitteena oli 1900-luvun alusta lähtien suomenkielisten kveenien ja saamelaisten täysimittainen norjalaistaminen. Tätä norjalaistamiseksi (fornorskning) kutsuttua politiikkaa on kommentoitu Norjassa koko politiikan soveltamisen ajan. Politiikan purkamisen ohjelmakseen ottanut tutkimus alkoi 1940-luvulla, ja 1970-luvulla koettiin yhteiskuntatieteellisen saamelaistutkimuksen aalto, jossa koululaitosta arvosteltiin yhtenä saamelaisia kolonisoivana tahona.

Historioitsijat tulivat jälkijunassa, ja vuonna 1981 ilmestyi Knut Einar Eriksenin ja Einar Niemen nykyään klassikkostatusta nauttiva teos Den finske fare. ${ }^{1}$ Kouluhistoriaa on Norjassa sittemmin tutkittu paljonkin, ja Den finske faren lainsäädäntöön ja muuhun normatiiviseen aineistoon ja tiedustelulähteisiin perustuva täydellisen assimilaation historiankuva on saanut kritiikkiäkin; norjalaistamispolitiikka ja -prosessi muodostavat kaksi eri historiallista ilmiötä, ja norjalaistumisprosessin hitaus oli tunnettu yhteiskunnallinen ilmiö jo 1800luvun lopussa. Vaikka lainsäädäntö tiukkeni alati, tiettyjä poikkeuksia siedettiin, ja esimerkiksi kristinoppia opetettiin toisinaan saameksi pitkään luterilaiseen lähetystyöperinteeseen nojaten. Lisäksi norjalaistamispolitiikka kohdistui voimakkaammin tiettyihin saamelaisryhmiin (merisaamelaiset) ja -alueisiin (etnisesti sekoittuneet rannikkoseudut) ja suuret osat Finnmarkista jäivät toimien ulkopuolelle, koska vuoteen 1898 saakka virkamiesten mukaan saamen kielen hallitseva asema teki norjalaistamisyritykset turhiksi. (Eriksen \& Niemi 1981; Andresen ym. 2021; Jensen 2005; Kortekangas 2017.)

1 "Suomen vaara" tai "suomalainen vaara", kirjan nimi viittaa Norjassa koettuun Suomen ja erityisesti fennomanian laajentumisideologian vaaraan. Tämän vaaran vuoksi Norjan pohjoisten raja-alueiden suomenkieliset kveenit, ja samalla myös saamelaiset, joutuivat tiukan assimilaatiopolitiikan piiriin. 
Voimakkaan assimilaation syyt olivat turvallisuuspoliittisia: Suomen ja Venäjän ajateltiin olevan potentiaalisia uhkia pohjoisilla rajaseuduilla, ja ei-norjalaiset vähemmistöt (saamelaiset ja suomea puhuvat kveenit) nähtiin kansallisen turvallisuuden vaarantavina elementteinä. Toisaalta mukana oli myös vahva norjalaistamisideologia, joka perustui romanttiseen kulttuuriseen nationalismiin, mutta osin myös ranskalaistyyppiseen kansalaisnationalismin ja demokratian ajatukseen: kaikille Norjan lapsille haluttiin tarjota opetusta, joka oli laadultaan ja sisällöiltään samanlaista ja takasi kaikille näennäisesti yhtäläiset lähtökohdat. (Jensen 2005; Myhre 1992; Eriksen \& Niemi 1981.) Saamen kieli palautettiin lakiin kirjatuksi opetuskieleksi 1959 kumoamalla aiempi laki ilman keskustelua Suurkäräjillä. Saamelaiset aloittivat pitkän kamppailun opetuksen saamelaissisällön lisäämiseksi ja turvaamiseksi.

Viimeaikainen tutkimus korostaa aiemman saamelaisten erityiskohteluun keskittyneen tutkimuksen sijaan Norjan kansakoulun "yleistä" norjalaistamislinjaa, joka perustui yksinkertaisesti Norjan kansakoululaitoksen tehtäville yhtenäisen norjalaisen kansan, valtion ja kansalaisten kasvattamiseksi. Kaikki vähemmistöt, myös saamelaislapset, jotka asuivat erityistoimien ulkopuolisilla alueilla, joutuivat tämän opetuksen kohteiksi. Uusi tutkimus lähestyy historiallista assimilaatiota myös modernisaation ja yleisen yhteiskuntakehityksen kautta sekä keskittyy poikkeamiin politiikasta. Viimeksi mainittuja olivat jatkuva apukielen eli saamen käyttö tietyissä kouluissa, sekä Norjassa korkealle arvostetun paikallisdemokratian muodon, kunnallisen itsehallinnon, käyttö internaattien perustamista vastaan. Esimerkkejä assimilaatiopolitiikan epäonnistumisesta nostetaan myös mielellään esiin. Yksi esimerkki tästä on saamelaisnuorten jatkokouluttautumisen myönteinen vaikutus saamelaiskielille ja -kulttuurille. Jatkokouluttautuminen tapahtui ennen kaikkea opettajaseminaareissa. Jo 1930-luvulta lähtien saamelaiset olivat myös vaatineet tasa-arvoista koulutusta sekä norjan että saamen kielellä. Sodanjälkeisen ajan saamelaisten esittämä kaksikielisen "pätevän kansalaisen" ("kompetent medborger") ihanne tulee uudessa tutkimuksessa kartoitetuksi norjalaistamispolitiikan purkamisen yhteydessä; äidinkielen osaamisen myötä saamelaisen tuli heittää häpeä omasta etnisyydestään. Toinen keino päästä häpeästä ja alemmuudentunteesta oli oppia ja opettaa lapsille norjan kieli ja näin päästä tasa-arvoiseksi yhteiskunnan osaksi sekä saada mahdollisuus nauttia samanmittaisesta kouluopetuksesta kuin muutkin oppilaat. (Andresen ym. 2021.) Näitä vaatimuksia ei uusimmassa historiantutkimuksessa enää kyseenalaisteta "vääränä", "kolonisoituna" tai "norjalaistuneena" tietoisuutena.

Vaikka assimilaatio oli voimakasta Norjassa aina 1900-luvun jälkipuoliskolle saakka, maassa oli toisaalta myös naapurimaita selkeästi vahvempi saamelainen vastustus sulauttamispolitiikkaa kohtaan. Norjalaistamispolitiikka selittää osan vastarinnasta. Nykytutkimus korostaa kuitenkin myös muita tekijöitä, kuten halua suojella saamelaisten kieltä, kulttuuria ja elinkeinoja (Andresen ym. 2021). Vastustajien johtajina oli saamelaisia opettajia, kuten Per Fokstad, joka ehdotti jo 1920-luvulla kokonaan saamenkielisten kansakoulujen perustamista, tosin tuloksetta. Tällaisia ehdotuksia kuultiin Fokstadin jälkeen toden teolla vasta 1900-luvun loppupuolella, joten hän oli todella aikaansa edellä.

Saamelaisten omaa aktiivisuutta korostava tutkimus laajentaa ja monipuolistaa aikaisempaa assimilaationarratiiviin perustuvaa kuvaa, mutta ei hylkää sitä kokonaan: assimilaatio-kertomukset ovat uusimmassa saamenhistorian kokonaisesityksessä mukana kokemushistorioina. Norjalaiset tutkijat eivät ole perinteisesti harrastaneet kolonisaatio-, kärsimys-, katoamis- ja kansanmurhahistorioita. Viime aikoina on kuitenkin myös siellä heräämässä tietoisuus siitä, että toimijuus- ja assimilaatio-historiat eivät ole toisiaan poissulkevia. (Jensen 2005; Ryymin \& Nyyssönen 2012; Kortekangas 2017; Olsen 2019; Nyyssönen 2019; Zachariassen 2011; Andresen ym. 2021.) 


\section{Kirkon rooli vahva Suomessa}

Suomen kansakoulujen saamelaispolitiikka muistutti Ruotsin tavallisia kansakouluja (ei siis nomadikouluja) siinä mielessä, ettei lainsäädännössä mainittu mitään kansakouluissa käyvistä saamelaislapsista. Suomen lainsäädäntö tosin tunnusti mahdollisuuden muun kuin suomenkielisen opetuksen järjestämiseen, mikä on ymmärrettävää, sillä merkittävä osa kansakouluista oli ruotsinkielisiä. Tätä lain kohtaa ei kuitenkaan käytännössä lähes koskaan sovellettu saamelaisten kohdalla. Utsjoella toimi tosin Outakosken ja Utsjoen kirkonkylän koulut, joissa saamelaisopettajat opettivat myös saameksi. Outakoskella näin tekivät isä ja poika Josef ja Hans Aslak Guttorm. Tutkimuksesta piirtyy kuva Suomesta eräänlaisena saamelaisen koulutuspolitiikan "laissez-faire" -tapauksena: muun muassa resurssipulasta ja saamelaisten varsinkin Norjaan verrattuna vähäisestä määrästä johtuen saamelaisten koulutus ei ikinä noussut samanlaiseksi prioriteetiksi kansallisella tasolla kuin Ruotsissa ja Norjassa. (Lehtola 2012; Kortekangas 2021.)

Suomen kansakouluverkosto levisi pohjoiseen hitaammin kuin Norjassa ja Ruotsissa. Resurssipulasta johtuen harvaanasutut pohjoiset alueet jätettiin kirkollisen opetuksen piiriin. Kirkon Lapin kylien välillä kiertävät "katekeettakoulujen" opettajat, katekeetat, käyttivät usein saamea opetuksessa. Näin ollen yhtäläisen kansanopetuksen Suomen pohjoisosiin ulottamisen viivästyminen suosi saamen kielen säilymistä, ja saamen kielen asema jopa parani 1900-luvun alkuvuosikymmeninä kirkon saamea kohtaan positiivisen asenteen myötä. (Kähkönen 1988; Lehtola 2012.) Kun kansakoulut lopulta toisen maailmansodan jälkeen ottivat vetovastuun opetuksesta myös Lapissa, assimilaatio kiihtyi koulujen tarjotessa opetusta pääasiassa vain Suomeksi. Yhtäläinen suomalainen kansalaisuusihanne levisi siis saamelaisalueille samaan aikaan kuin saamenkielinen opetus väistyi ja kuihtui. (Kähkönen 1988; Lehtola 2012; Kortekangas 2017.)

Suomessa saamelaislasten koulutusta 1900-luvun alussa on tutkittu varsin vähän naapurimaihin verrattuna. Syitä tähän voi hakea ajanjaksosta - Suomen "dramaattisin" assimilaatiopolitiikka oppilasasuntoloineen ajoittui vasta toista maailmansotaa seuraaviin vuosiin. Asuntolat liittyivät sinällään hyvää tarkoittavaan yhtäläisen peruskoulutuksen takaamisen politiikkaan. Asuntolahistoriat pysyivät tuntemattomina suurelle yleisölle, osin saamelaisen koulutus- ja valtiomyönteisyyden vuoksi, ja osin siksi, että asuntolakouluja oli vielä paljon muuallakin Suomessa. Toisaalta saamelaisten määrä Suomessa oli ja on edelleen pienempi kuin Ruotsissa ja Norjassa. Koulutuspolitiikka kiinnitti vähemmän huomiota saamelaisten "ongelmaan" kuin naapurimaissa, ja koulutushistoriallisen tutkimuksen vähyys heijastelee tätä historiallista todellisuutta. Vasta nuoremman saamelaispolven esiinmarssi saamelaisliikkeessä ja varsinkin tutkimuksessa 1960- ja 1970-luvuilla toivat esiin kielen- ja kulttuurinmenetykset, ja saamelaiset alkoivat vaatia ja laatia ratkaisuja koululaitoksen muuttamiseksi. (Nyyssönen 2014.) Nämä kasvatuksen ja koulutuksen dekolonisaatio-vaatimukset ovat kasvaneet: Kasvatustieteen puolella saamelaisten koulutukseen ja sen historiaan ovat kiinnittäneet huomiota muun muassa Pigga Keskitalo, Merja Paksuniemi, Rauna RahkoRavantti sekä Mariakaisa Laiti (Paksuniemi ja Keskitalo 2019; Marikaisa Laiti 2019; Rahko-Ravantti 2016).

\section{Saamelainen koulunkäynti ja sitä koskeva tutkimus nyt ja tulevaisuudessa}

Nykyään Suomessa, Norjassa ja Ruotsissa on lainsäädännön perusteella mahdollista käydä koko opinpolku saameksi, tosin vain kunkin maan virallisesti rajatuilla saamelaisalueilla pohjoisessa. Tämä mahdollisuus on vain muutaman vuosikymmenen ikäinen, ja valtaväes- 
töön sulautuminen oli yleistä kouluissa vielä aivan hiljattain, koska koulut muuten seurasivat enemmistökulttuurin mallia. Saamelaisten koulutukseen erikoistuva tutkimus on viime aikoina korostanut, että vaikka saamenkielisen opetuksen tila on parantunut, saamelainen historia ja kulttuuri ovat edelleen heikosti edustettuina opintosuunnitelmissa ja oppisisällöissä (mm. Rahko-Ravantti 2016). Viime aikoina tutkijat ovat huomioineet, että suuri osa saamelaislapsista käy koulua valtaväestöjen parissa saamelaisalueen ulkopuolella. Näin ollen saamelaisia oppisisältöjä pitäisi tämän tutkimuksen mukaan sisällyttää myös yleisiin opintosuunnitelmiin kaikissa Pohjoismaissa. Tällainen saamelaislähtöinen opetus ottaisi huomioon saamelaisten historian, kielen ja kulttuurin, sen sijaan että oppimateriaali yksinkertaisesti käännettäisiin valtakielistä saameksi (Keskitalo ym. 2013; Olsen 2019; Svonni 2015; Kemi Gjerpe, 2018.)

Eräs esimerkki uudenlaisesta ajattelusta saamelaisten koulunkäynnin alueella on syksyllä 2018 toimintansa aloittanut kaksikielinen, saamen- ja suomenkielinen linja Pasilan peruskoulussa Helsingissä. Helsinki, Tukholma ja Oslo ovat nykyään saamelaisen väestön asuinluvultaan suurimpia keskuksia. Onkin luontevaa, että saamenkielistä opetusta kehitetään myös näissä, hallinnollisesti saamelaisalueen ulkopuolella sijaitsevissa suurkaupungeissa.

Saamelaisten kohentunut asema koulutuksen saralla on pitkän ja vaikean työn tulos. Koulu- ja opetuspolitiikka ovat edelleen tärkeitä ja ajankohtaisia puheenaiheita saamelaisalueella, sillä saamen kielen ja kulttuurin asema on edelleen vaikea valtayhteiskunnan ja yksikielisyyden paineissa. Osa tutkijoista ja saamelaisista aktivisteista kuvaavat näitä edelleen vaikuttavia rakenteita kolonialismin ja asuttajakolonialismin käsitteiden kautta. Näissä määritelmissä valtaväestöt ja valtiot näyttäytyvät siirtomaavaltoina, jotka edistivät ja edistävät omia pyrkimyksiään saamelaisalueella saamelaisten omista mielipiteistä välittämättä (Nyyssönen \& Kortekangas 2020.) Tämä on myös uusi tapa politisoida kouluhistoria, ja näin ollen kulttuurisen hävittämisen ja katoamisen kertomus on palannut saamelaisten akti vismiin ja myös tutkimusretoriikkaan (esim. Junka-Aikio, Nyyssönen ja Lehtola, painossa). Kolonialismikäsitteen yhteydessä esiintyy myös koulu- ja asuntolakeskustelun uutta välineellistämistä, eli käyttöä poliittisiin tarkoitusperiin niin sanotusti puhtaasti tutkimuksellisten lähtökohtien sijaan.

Viime vuosina saamelaisten koulutushistoriallinen tutkimus on siis keskittynyt pitkälti kuvan laajentamiseen ja tietoisuuden lisäämiseen historian kompleksisuudesta, jossa nähdään toimijuuden ja toimijoiden moninaisuutta yksinkertaistettujen "sortaja" ja "sorrettu" tyyppisten kategorioiden sijaan. Toisaalta alkuperäiskansametodologiaan ja dekolonisointivaatimuksiin perustuva tutkimussuuntaus kulkee osittain vastakkaiseen suuntaan, korostaessaan vahvojen roolien ja kategorioiden tarpeellisuutta vastuukysymyksissä ja tavoitteissaan uudenlaisen, saamelaisten omaan kulttuurin perustuvan tutkimuksen ja koulutuksen edistämiseksi. Kunkin maan tutkimus keskittyy edelleen pitkälti kansallisvaltion ja saamelaisten välisiin suhteisiin koulutuksen saralla. Tämä kansallisen tutkimuskehyksen vahvuus hankaloittaa yhteispohjoismaisten ja ylirajaisten tutkimusten tuottamista. Viime vuosina tutkijat ovat alkaneet korostaa myös tällaisen ylirajaisen saamelaisen koulutushistorian tutkimisen tärkeyttä (esim. Kortekangas ym. 2019).

\section{Kirjallisuus}

Allemann, Lukas 2019. The Perspective of Former Pupils. Indigenous Children and Boarding Schools on the Kola Peninsula, 1960s to 1980s. In Kortekangas, Otso et al. 
(eds.), Sámi Educational History in a Comparative International Perspective. Cham: Palgrave Macmillan, 83-104. https://doi.org/10.1007/978-3-030-24112-4 6

Andresen, Astri, Evjen, Bjørg ja Ryymin, Teemu (red.) 2021. Samenes historie fra 1751 til 2010. Cappelen Damm Akademisk.

Elenius, Lars 2006. Nationalstat och minoritetspolitik. Samer och finskspråkiga minoriteter $i$ ett jämförande nordiskt perspektiv. Lund: Studentlitteratur.

Eriksen, Knut Einar ja Niemi, Einar 1981. Den finske fare. Sikkerhetsproblemer og minoritetspolitikk $i$ nord 1860-1940. Oslo: Universitetsforlaget.

Henrysson, Sten 1993. Darwin, ras och nomadskola. Motiv till kåtaskolreformen 1913. Uumaja: Uumajan yliopisto.

Jensen, Eivind Bråstad 2005. Skoleverket og de tre stammers møte. Tromssa: Eureka.

Junka-Aikio, Laura, Nyyssönen, Jukka \& Veli-Pekka Lehtola (in print). Sámi research in transition - an introduction. In Laura Junka-Aikio, Jukka Nyyssönen \& Veli-Pekka Lehtola (eds.), Sámi Research in Transition: Knowledge, Politics and Social Change. London \& New York: Routledge.

Kemi Gjerpe, Kajsa 2018. From indigenous education to indigenising mainstream education. FLEKS - Scandinavian Journal of Intercultural Theory and practice 5 (1), 118. https://doi.org/10.7577/fleks.2190

Keskitalo, Pigga, Määttä, Kaarina, Uusiautti, Satu 2013. Sámi Education. Frankfurt a. M.: Peter Lang. https://doi.org/10.3726/978-3-653-01975-9

Paksuniemi, Merja ja Keskitalo, Pigga 2019. Christian Morality and Enlightenment to the Natural Child: Third-Sector Education in a Children's Home in Northern Finland (1907-1947). In Otso Kortekangas, Pigga Keskitalo, Jukka Nyyssönen, Andrej Kotljarchuk, Merja Paksuniemi \& David Sjögren (eds.), Sámi Educational History in a Comparative International Perspective. Cham: Palgrave Macmillan, 161185. https://doi.org/10.1007/978-3-030-24112-4_10

Kortekangas, Otso 2017. Tools of teaching and means of managing : educational and sociopolitical functions of languages of instruction in elementary schools with Sámi pupils in Sweden, Finland and Norway 1900-1940 in a cross-national perspective. Turku: Iloinen tiede.

Kortekangas, Otso 2021. Language, Citizenship, and Sámi Education in the Nordic North, 1900-1940. Montreal: McGill-Queen's University Press. https://doi.org/10.2307/ j.ctv1gm00f2

Kortekangas, Otso, Keskitalo, Pigga, Nyyssönen, Jukka, Kotljarchuk, Andrej, Paksuniemi, Merja ja Sjögren David (eds.) 2019. Sámi Educational History in a Comparative International Perspective. Cham: Palgrave Macmillan. https://doi.org/ 10.1007/978-3-030-24112-4

Kotljarchuk, Andrej 2019. Indigenous People, Vulnerability and the Security Dilemma: Sámi School Education on the Kola Peninsula, 1917-1991. In Otso Kortekangas, Pigga Keskitalo, Jukka Nyyssönen, Andrej Kotljarchuk, Merja Paksuniemi \& David Sjögren (eds.), Sámi Educational History in a Comparative International Perspective. Cham: Palgrave Macmillan, 63-82. https://doi.org/10.1007/978-3-03024112-4 5

Kähkönen, Esko 1988. Katekeetat Suomen Lapissa 200 vuotta. Rovaniemi: Lapin korkeakoulu.

Laiti, Marikaisa. History of Early Childhood Education in the Sámi Language in Finland. In Otso Kortekangas, Pigga Keskitalo, Jukka Nyyssönen, Andrej Kotljarchuk, Merja Paksuniemi \& David Sjögren (eds.), Sámi Educational History in a Comparati- 
ve International Perspective. Cham: Palgrave Macmillan, 187-206. https://doi.org/ 10.1007/978-3-030-24112-4 11

Lantto, Patrik 2000. Tiden börjar på nytt. En analys av samernas etnopolitiska mobilisering i Sverige 1900-1950. Uumaja: Uumajan yliopisto.

Lehtola, Veli-Pekka 2012. Saamelaiset suomalaiset. Kohtaamisia 1896-1953. Helsinki: SKS.

Myhre, Reidar 1992. Den norske skoles utvikling. Idé og virkelighet. Oslo: Gyldendal.

Mörkenstam, Ulf 1999. Om "Lapparnes privilegier". Föreställningar om samiskhet $i$ svensk samepolitik 1883-1997. Tukholma: Tukholman yliopisto.

Nordblad, Julia 2013. Jämlikhetens villkor. Demos, imperium och pedagogik i Bretagne, Tunisien, Tornedalen och Lappmarken, 1880-1925. Göteborg: Göteborgin yliopisto.

Nyyssönen, Jukka 2014. Suomalainen koululaitos ja saamelaiskysymys. Teoksessa Pigga Keskitalo, Veli-Pekka Lehtola \& Merja Paksuniemi (toim.), Saamelaisten kansanopetuksen ja koulunkäynnin historia Suomessa. Turku: Siirtolaisuusinstituutti, 154-174.

Nyyssönen, Jukka 2019. Narratives of Sámi School History in Finland: Assimilation and Empowerment. In Otso Kortekangas, Pigga Keskitalo, Jukka Nyyssönen, Andrej Kotljarchuk, Merja Paksuniemi \& David Sjögren (eds.), Sámi Educational History in a Comparative International Perspective. Cham: Palgrave Macmillan, 4762. https://doi.org/10.1007/978-3-030-24112-4_4

Nyyssönen, Jukka ja Kortekangas, Otso 2020. Siirtomaapolitiikkaa Saamenmaalla? Historiografisia näkökulmia Suomesta ja Ruotsista. Historiallinen Aikakauskirja 4, 545-550.

Olsen, Torjer 2019. Sámi Issues in Norwegian Curricula: A Historical Overview. In Otso Kortekangas, Pigga Keskitalo, Jukka Nyyssönen, Andrej Kotljarchuk, Merja Paksuniemi \& David Sjögren (eds.), Sámi Educational History in a Comparative International Perspective. Cham: Palgrave Macmillan, 125-141. https://doi.org/ 10.1007/978-3-030-24112-4 8

Pusch, Simone 1998. Nomadskolinspektörerna och socialdarwinismen 1917-1945. Uumaja: Uumajan yliopisto.

Rahko-Ravantti, Rauna 2016. Saamelaisopetus Suomessa. Tutkimus saamelaisopettajien opetustyöstä suomalaiskouluissa. Lapin yliopisto, Kasvatustieteiden tiedekunta

Ryymin, Teemu \& Nyyssönen, Jukka 2012. Fortellinger i nordnorsk minoritetshistorie. Historisk tidsskrift 91 (4), 541-568. https://doi.org/10.18261/ISSN1504-2944-2012-04$\underline{04}$

Sjögren, David 2010. Den säkra zonen. Motiv, åtgärdsförslag och verksamhet i den särskiljande utbildningspolitiken för inhemska minoriteter 1913-1962. Uumaja: Uumajan yliopisto.

Svonni, C. (2015). At the Margin of Educational Policy. Sámi/Indigenous Peoples in the Swedish National Curriculum 2011. Creative Education 6 (9), 898-906. https:// doi.org/10.4236/ce.2015.69091

Svonni, Charlotta 2017. Samisk utbildning i förändring: nomadskolan och processen för samer att bli likvärdiga samhällsmedborgare. Teoksessa Liliequist, Marianne \& Cocq, Coppélie (toim.) Samisk kamp. Kulturförmedling och rättviserörelse. Uumaja: H:ström Text Kultur, 223-251.

Zachariassen, Ketil 2011. Samiske nasjonale strategar. Den samepolitiske opposisjonen $i$ Finnmark, ca. 1900-1940. Tromssa: UiT Norges arktiske universitet.

Zmyvalova, Ekaterina ja Outakoski, Hanna. The Development of Sámi Children's Right to Learn Sámi in the Russian School Context. In Otso Kortekangas, Pigga Keskitalo, Jukka Nyyssönen, Andrej Kotljarchuk, Merja Paksuniemi \& David Sjögren (eds.), 
Katsaus

Sámi Educational History in a Comparative International Perspective. Cham: Palgrave Macmillan, 105-123. https://doi.org/10.1007/978-3-030-24112-4_ 7

FT Otso Kortekangas on koulutushistoriaan erikoistunut tutkija Tukholman Kuninkaallisessa teknillisessä korkeakoulussa.

Dr. artium Jukka Nyyssönen on saamenhistorian tutkija, joka työskentelee vanhempana tutkijana NIKUssa (Norsk institutt for kulturminneforskning)Tromssassa. 